\title{
Deformation and "deformation quiescence" prior to the Chi-Chi earthquake evidenced by DInSAR and groundwater records during 1995-2002 in Central Taiwan
}

\author{
Jiun-Yee Yen, Kun-Shan Chen, Chung-Pai Chang, and Sin Mei Ng \\ Center for Space and Remote Sensing Research, National Central University, No. 300, Jhongda Rd., Jhongli City, Taoyuan County 320, Taiwan
}

(Received August 2, 2005; Revised February 10, 2006; Accepted February 13, 2006; Online published July 26, 2006)

\begin{abstract}
Deformation of Central Taiwan between 1997 and 2002 was investigated using radar interferometry to construct the deformation rate time series before, during, and after the Chi-Chi earthquake. The deformation rate time series was compared to the time series of groundwater level in the monitoring wells of Yuanlin and Tzushan in order to investigate the relation between the geodetic observations and the groundwater levels. The deformation pattern of Central Taiwan generally forms a half-elliptical pattern, with the eastern half of the elliptical shape cut away by the north-south trending Chelungpu fault. Along a selected profile of $10 \mathrm{~km}$ near the Chelungpu Fault of Central Taiwan, the differential range change was measured and recalculated into deformation rates. The year-to-year deformation rates near the Chi-Chi earthquake ranged between 1.5 and $3 \mathrm{~cm} /$ year in most years except for the years between 1999 and 2000, which showed more than $5 \mathrm{~cm} /$ year deformation rates along the profile. Prior to the high deformation rate shown during the coseismic image pair, the deformation rate was low, as shown on the other image pairs. This variation in deformation rate coincides with the recorded trend in the level of groundwater in two monitoring wells in the Yuanlin area. The low deformation rate prior to the Chi-Chi earthquake may — partially — be explained by this lowering in groundwater level.
\end{abstract}

Key words: Synthetic aperture radar, radar interferometry, groundwater, Chi-Chi earthquake.

\section{Introduction}

The Mw 7.6, September 21, 1999 Chi-Chi earthquake in Taiwan was one of the largest earthquakes recorded there in recent history. It ruptured through the Chelungpu fault running north-south along the western part of the major mountain belt in Taiwan and produced surface rupture approximately $100 \mathrm{~km}$ in length along the fault, with horizontal displacement of up to $10.1 \mathrm{~m}$ (Tsai et al., 2001; Yu et al., 2001). The extent of the damage, the amount of deformation, and the coseismic deformation patterns have been reported by many international research groups. However, most of these studies focused on the co-seismic deformation and fault parameterization (Angelier et al., 2003a, b; Chang et al., 2000; Chang et al., 2004; Hsieh et al., 2001; Jang et al., 2002; Kao et al., 2002; Lee et al., 2001; Lin et al., 2001; Ma et al., 2003; Mouthereau et al., 2001; Shin, 2000; Tanaka et al., 2002), and very little attention was paid to the deformation pattern and the changes in the deformation pattern before, during, and after the earthquake. Monitoring the surface deformation in the time period in the region of high seismicity improves our understanding of the relation between the seismicity and surface deformation. This lack of information in monitoring the surface deformation in the area of the Chi-Chi earthquake is partly attributable to the lack of proper geodetic equipment and techniques at

Copyright (c) The Society of Geomagnetism and Earth, Planetary and Space Sciences (SGEPSS); The Seismological Society of Japan; The Volcanological Society of Japan; The Geodetic Society of Japan; The Japanese Society for Planetary Sciences; TERRAPUB. the time. Although GPS data are currently available in Taiwan (Yu et al., 2001, 2003), most of the modern geodetic equipment was installed in Central Taiwan subsequent to the 1999 Chi-Chi earthquake. In addition, existing GPS data is not comprehensive enough to cover the vast area affected by the ruptured fault. Consequently, the geodetically measured deformation history leading to this earthquake is still largely unknown. Information assembled by means of other geodetic surveys, such as spirit leveling, was also not available at the time and would be subject to similar limitations at those of the GPS. As a result, we have employed radar interferometry to investigate surface deformation before, during, and after the Chi-Chi earthquake.

In addition to measuring deformation using satellite geodesy, we also used two records of groundwater level in nearby monitoring wells to investigate the relationship between surface deformation and the hydrogeological response of the groundwater level. The results of earlier investigations have indicated that earthquakes affect the groundwater level both locally and in areas hundreds of kilometers distant. However, most of the research has focused on the coseismic responses of the groundwater level (Chia et al., 2001; Hsu and Tung, 2005; Huang et al., 2004; Matsumoto et al., 2003; Montgomery and Manga, 2003; Wang et al., 2004a; Wang et al., 2005) or the chemical and isotopic composition of the groundwater (Quattrocchi et al., 2000; Song et al., 2003; Wang et al., 2005). Since the records of groundwater level reflect the poroelastic property of the aquifer, the former can be used as a low-resolution 


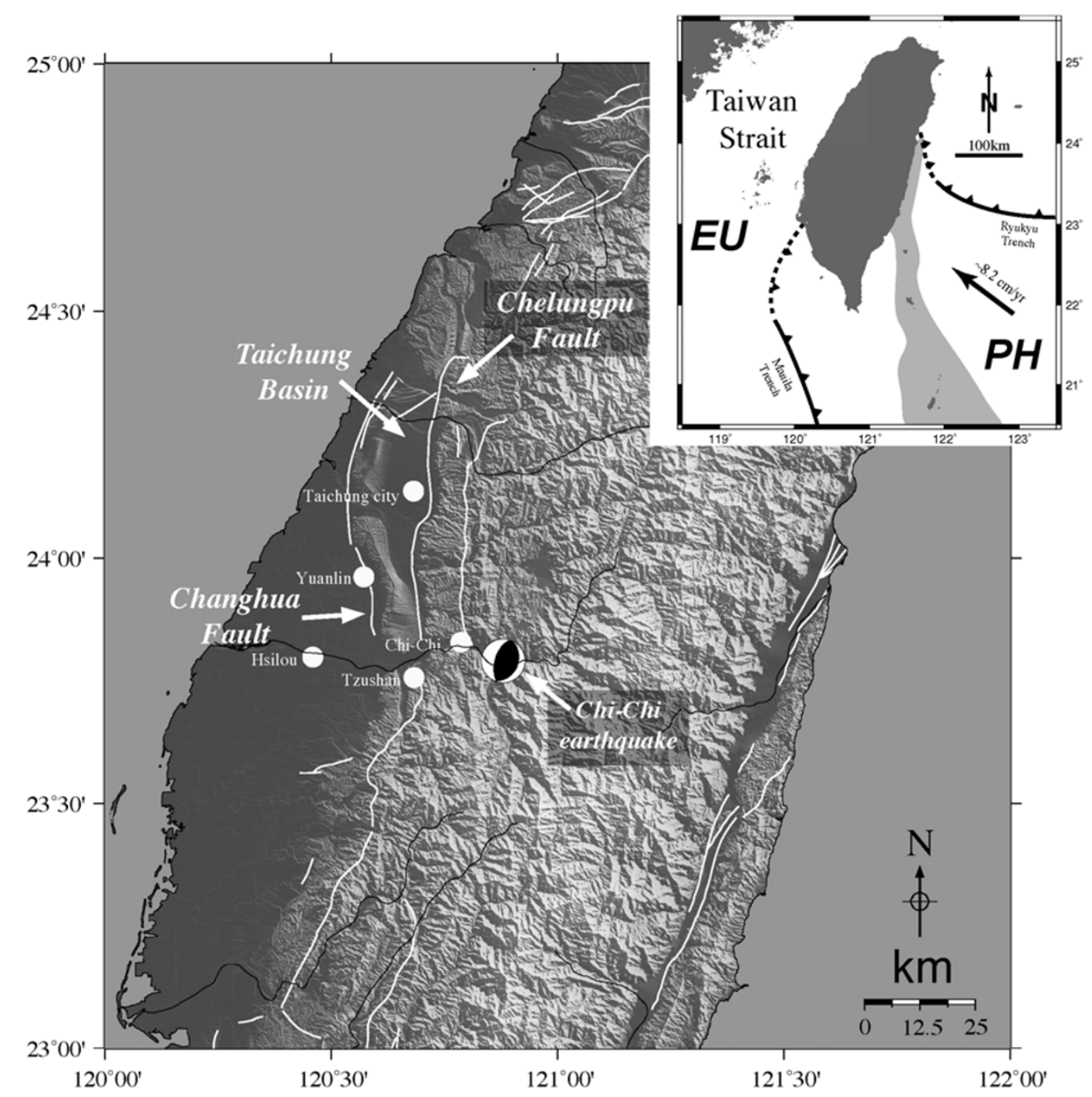

Fig. 1. Active faults in Central Taiwan overlain on top of shade relief map. Study areas are located at the western end of the fast-growing mountain ranges caused by the collision between the Eurasian plate and the Philippine Sea plate. The location and focal mechanism of the Chi-Chi earthquake is also shown on this map. Inset shows the tectonic configuration near Taiwan. EU: Eurasian plate; PH: Philippine Sea plate.

strainmeter (Roeloffs et al., 2003). The relation between the surface deformation and groundwater level is then an interesting topic since it is possible to cross-investigate the deformation both on the surface and in the ground.

\section{Geological Background}

The island of Taiwan is located between the southeastern Eurasian plate and western corner of the Philippine Sea plate (Fig. 1). To the east and northeast of Taiwan, the Philippine Sea plate is subducting beneath the Eurasian plate, creating the Rykyu subduction system and the Okinawa trough; to the south of Taiwan the South China Sea oceanic crust (part of the Eurasian plate) is subducting to the east beneath the Philippine Sea plate, creating the Manila subducting system and Luzon Volcanic arc. As such, the island of Taiwan marked a location of change of subduction polarity and formed a collisional mountain belt. The Philippine Sea plate is currently moving in the direction of $307^{\circ}$ azimuth at approximately 7-8 cm/year (Seno et al., 1993; Yu et al., 1997) and carries the north-south trending Luzon arc along to form a collisional mountain belt. Since the stable Eurasian continental margin is approximately trending northeast-southwest, the convergence of the Luzon arc and stable Eurasian margin formed an oblique arc-continent collision (Suppe, 1984). The effect of the oblique collision is clearly indicated by the geomorphological and tectonic features of onland Taiwan. Overall, the high relief on the island of Taiwan indicates the rapid mountain building process brought about by the high convergent rate between the Philippine Sea plate and the Eurasian plate; however, in the northern part of the island post-orogenic extension has been reported (Teng, 1996), while in the southern part of Taiwan and offshore southern Taiwan, incipient collision has just taken place (Lundberg et al., 1997). The deformation caused by the collision is mostly absorbed in the eastern part of the island (Yu et al., 1997) where the collided Philippine Sea plate and northern extension of Luzon arc pushed the buoyant material of the subducting Eurasian plate to form the island of Taiwan (Dahlen et al., 1984; Suppe, 1984). Consequently, the zone of deformation is brought westward by the continuing westward motion of the Philippine Sea plate and the island of Taiwan. The complex tectonic set- 


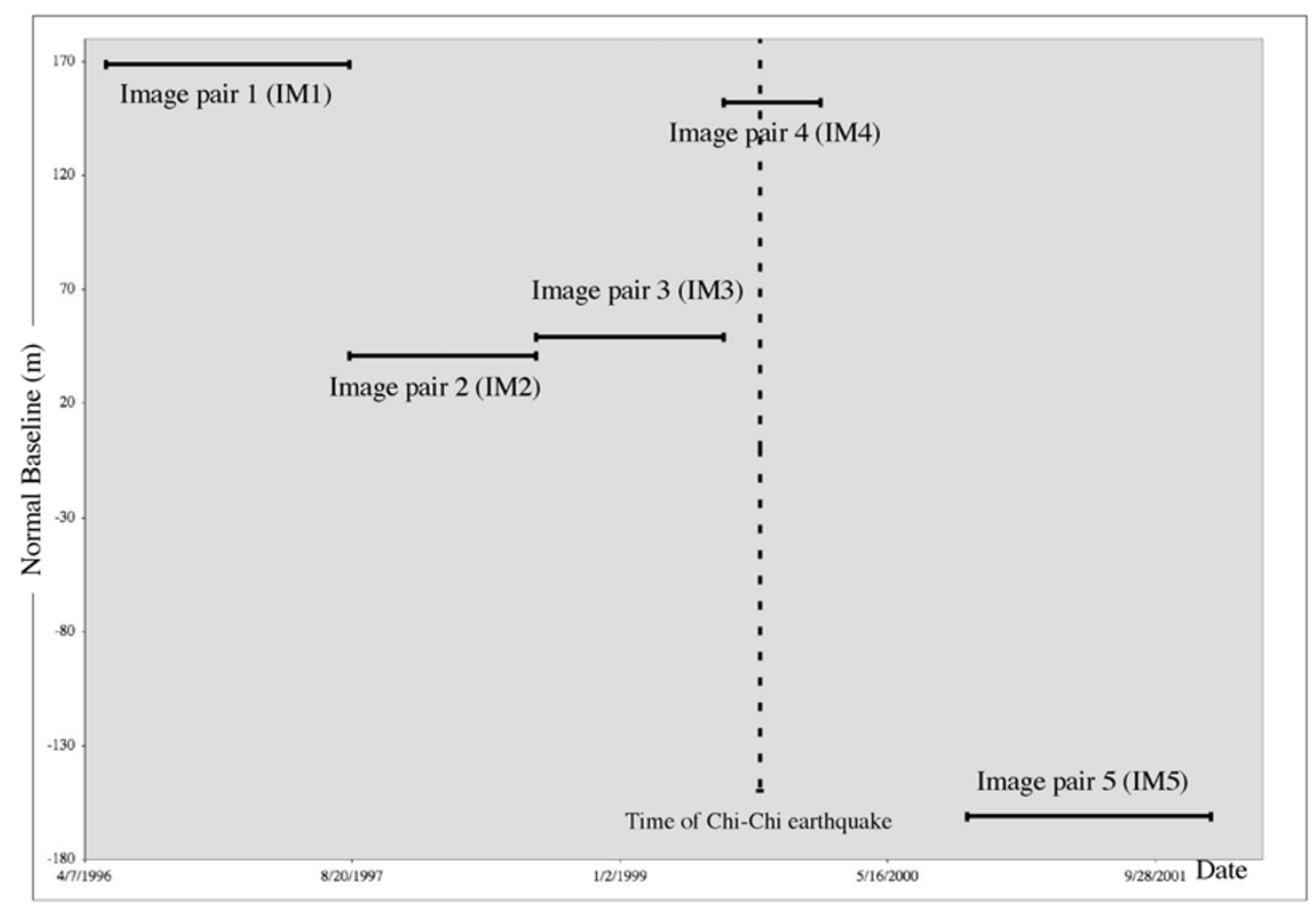

Fig. 2. Normal baseline and temporal extent of each image pair used in this study. The vertical axis is the normal baseline and the horizontal axis is the temporal baseline. Dashed line indicates the date of the Chi-Chi earthquake.

ting and constant westward movement of the material are important factors for the high seismicity in and around the island of Taiwan, and an understanding of this tectonic setting will ultimately contribute to our better understanding of the underlying principles of deformation that resulted in the island of Taiwan.

\section{Methods}

\subsection{DInSAR analyses}

By precisely determining the positions of the satellite when the radar images were taken and by recording the differences in the phase signals, the technique of space-borne differential interferometry is capable of revealing subtle large-area changes with a high precision (Burgmann et al., 2000; Massonnet and Feigl, 1998). For the DInSAR [differential synthetic aperative radar (SAR) interferometry] analyses in this study, European remote sensing (ERS) radar images were used to explore the deformation in the Central Taiwan area. ERS satellites launched by the European Space Agency in 1993 and 1995, respectively, have been used to explore the use of SAR as a tool to repeatedly observe the surface of the Earth. Radar interferometry by means of SAR has become an important geodetic tool for monitoring the surface deformation since the launching of these satellites. In this study we used six images from track 232 , frame 3123 to obtain five image pairs that span the period from 1995 to 2002 .

The duration of each image pair was purposefully chosen to approximate 1 year in order to minimize possible variations in atmospheric conditions and disparity caused by differences in the time scale of each image pair. The information provided by the radar images chosen is given in Fig. 2 and, on the respective interferogram, in Fig. 3. We adopted the two-pass method using DIAPASON software developed by CNES (Centre National d'Etudes spatiales) to produce the interferograms used in this study. The digital elevation model (DEM) used during the process has a grid resolution of $40 \mathrm{~m}$.

\subsection{Time series of groundwater level}

It has been reported that the crustal deformation measured by geodetic means correlate with the variations in the groundwater level and that the change on groundwater level can be explained as the poroelastic response of earthquakeinduced volumetric strain (Akita and Matsumoto, 2004; Bawden et al., 2001; King et al., 1999; Roeloffs et al., 2003). Therefore, by examining the records of groundwater level, it is possible to deduce the approximate change in the strain in the crust at the precise location of the aquifers. The Water Resource Agency of Taiwan has been working on establishing the Groundwater Monitoring Network System in the major alluvial fans around the island since 1992 in order to manage the water resource and mitigate the problem of land subsidence caused by the groundwater withdrawal. Previous investigations have focused on the coseismic change in the level and chemical contents of groundwater in the spatial domain of Central Taiwan (Chia et al., 2001; Lee et al., 2002; Lin et al., 2004; Song et al., 2003; Wang et al., 2001, 2004a, b, 2005). However, the history of the groundwater level within the framework of monitoring individual wells has not been reported in the literature, particularly with respect to the time preceding the Chi-Chi earthquake. We compared the groundwater level of two monitoring wells (Tzushan well, which is located on the hanging wall of the Chelungpu fault that caused the Chi-Chi earthquake, and Yuanlin well, which is located approximately $30 \mathrm{~km}$ to the west of the fault; see Fig. 1 for 

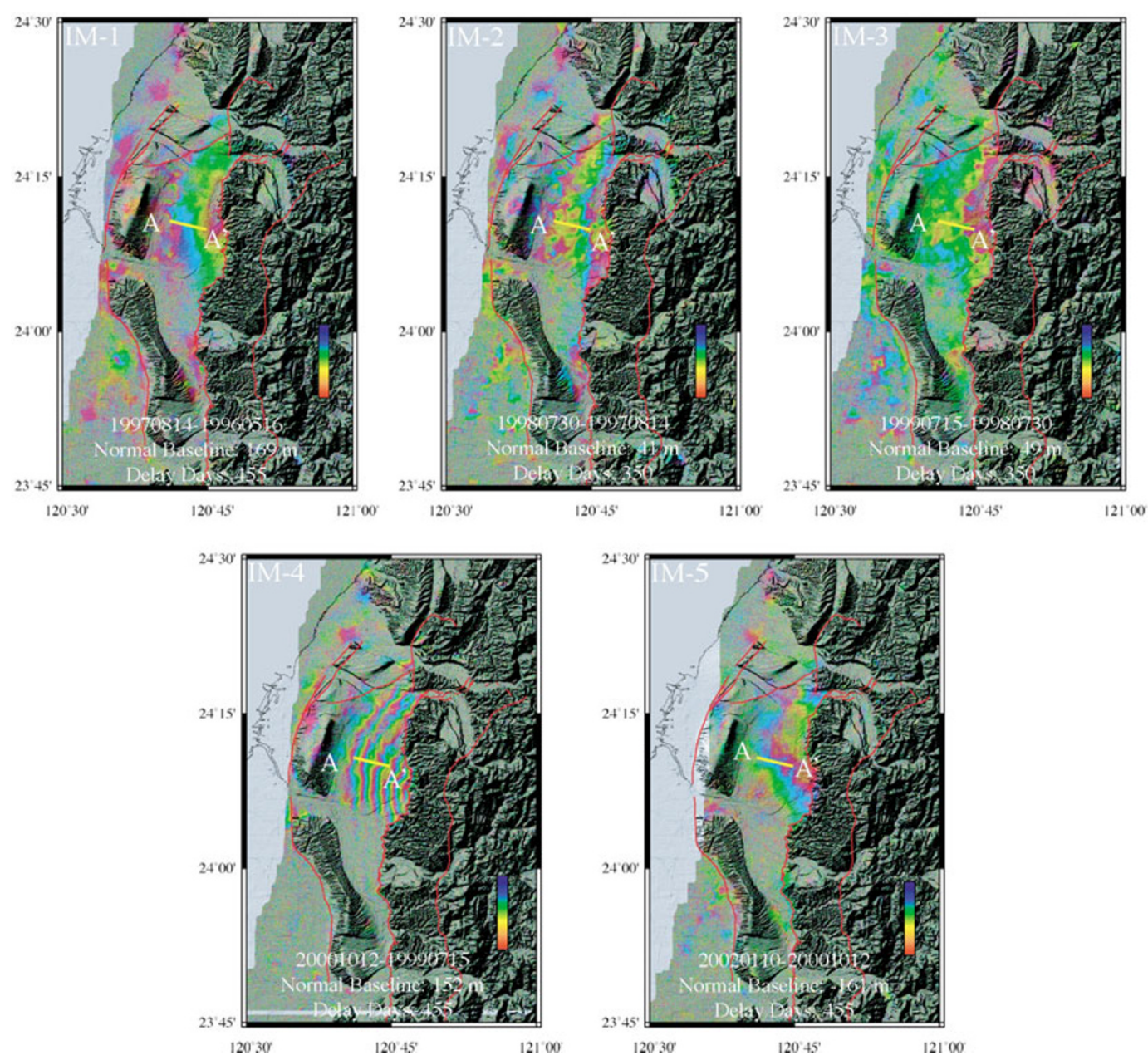

Fig. 3. Five interferograms of the Taichung Basin were generated for this study. The coverage of time by these interferograms is from 1996 to 2002.

the locations of both wells) to determine whether there was a trend with the same polarity of rise and fall and to compare this trend, if present, to the precipitation data for the Taichung Basin of Central Taiwan.

\section{Analytical Results}

Five interferograms for Central Taiwan (Fig. 3) were generated; Figure 2 shows their normal baseline and temporal baseline. The eastern half of the coverage area is the mountainous region of Taiwan and is mostly unpopulated, with extensive dense vegetation. Consequently, the coherence between two radar images is poor, with little meaningful signal for this part of the coverage area through all five interferograms. In the central part of the coverage area is the Taichung Basin, which is the most populated area in Central Taiwan. Most of the Taichung Basin lies between 60 and $90 \mathrm{~m}$ a.s.l. This low relief encourages the urbanization of the area and, consequently, presents a favorable situation for the coherence of radar signals. Therefore, in Taichung Basin, the interferometric signals are coherent and clear in all of the image pairs. The interferograms generated from the five image pairs were overlain on top of the shaded relief topographic map of the Central Taiwan region; the combined maps were then overlain by the active faults (Lin et al., 2000).

The amount of deformation along profile $\mathrm{A}-\mathrm{A}^{\prime}$ in Fig. 3 can be summarized as follows: within the Taichung Basin, which is bound by the Chelungpu fault to the east and the Paguashan and the Changhua faults to the west (Fig. 1), the maximum amount of deformation takes place in image pair 4 (Fig. 3; referred to as IM-4) at about $20 \mathrm{~cm}$ in the footwall area during the time coverage of this image pair. This amount of deformation was expected because IM-4 represents the coseismic deformation of the Chi-Chi earthquake. Conversely, both IM-1 and IM-2 have about one interferometric fringe within the Taichung Basin in the footwall area during their coverage time, respectively. During the time of IM-3, the amount of deformation was low-less than one full cycle of interferometric fringe is in the footwall area of IM-3. A similar pattern is seen in IM-5, which spans the period from immediately after the earthquake to early 2002 .

In order to compare the relative amount of deformation and deformation rate, we extracted deformation information from the five interferograms along the profile $\mathrm{A}-\mathrm{A}^{\prime}$; the raw phase information was then unwrapped and converted to slant range change along this profile (Fig. 4). The locality of the profile was chosen to obtain deformation information without obvious noise on all five interferograms along the profile. Noise due to low coherence often introduces error upon unwrapping of the phase signals obtained from the interferograms. We then calculated the average deformation rate along the profile for each image pair. The deforma- 


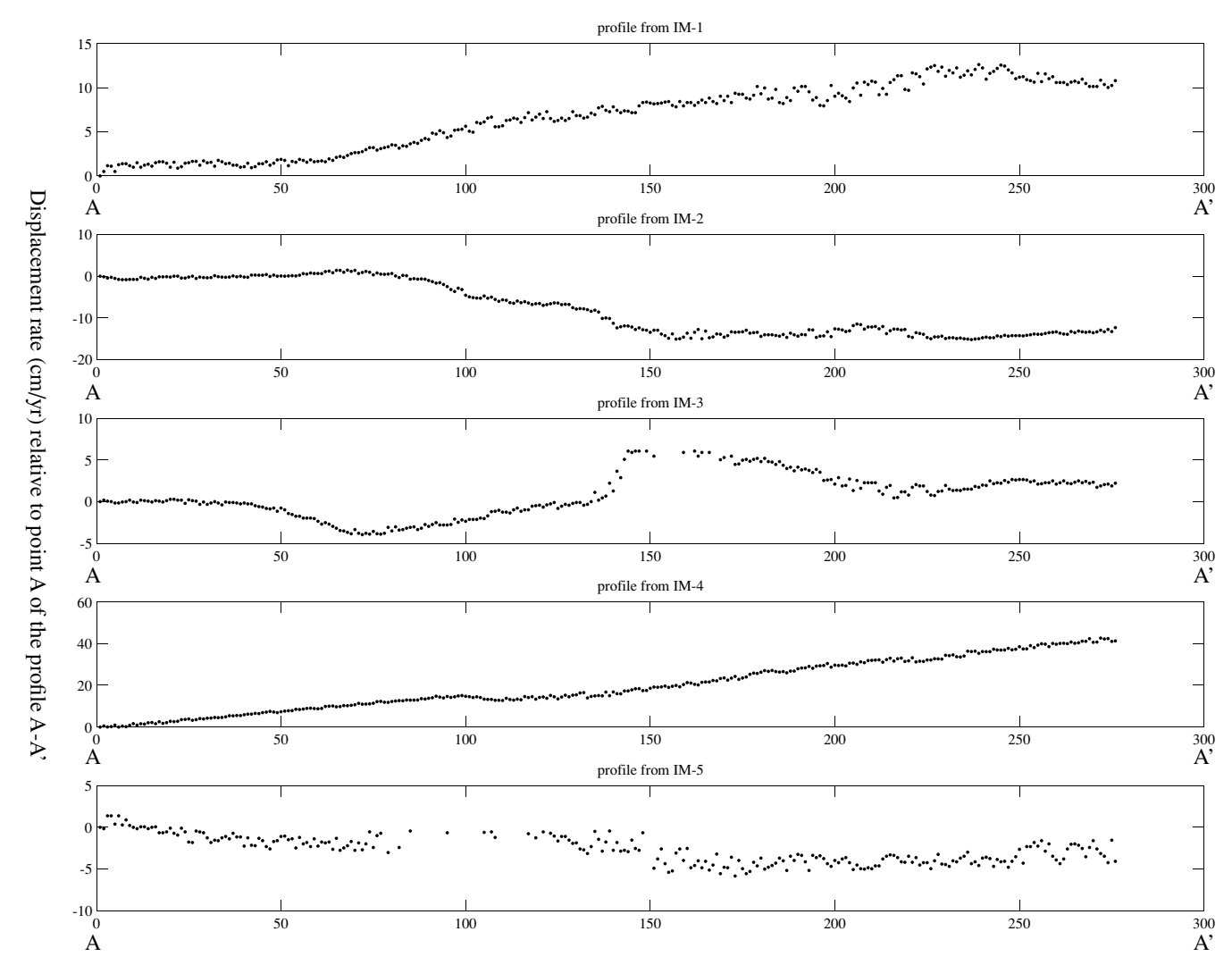

Fig. 4. Unwrapped profiles extracted from profile A-A' shown in Fig. 3. The vertical axis is the range direction in centimeters per year relative to the first point in the profile; the horizontal axis is pixel.

tion rates along profile $\mathrm{A}-\mathrm{A}^{\prime}$ within the Taichung Basin in the footwall area of the Chelungpu fault are shown in Fig. 5. The deformation in the footwall area of Taichung Basin was about $3 \mathrm{~cm} /$ year along the profile before the Chi-Chi earthquake, dropping to approximately $1 \mathrm{~cm} /$ year immediately before this earthquake. In IM-4, which spans the Chi-Chi earthquake, the deformation rate can be seen to have been more than $5 \mathrm{~cm} /$ year, dipping down to $1 \mathrm{~cm} /$ year after the Chi-Chi earthquake.

\subsection{Groundwater}

Daily groundwater levels from January 11995 to December 31, 2002, as recorded and archived by the Water Resource Agency of Ministry of Economic Affairs, were compared with the result from DInSAR. The coseismic and postseismic responses shown by the groundwater level, as previously studied (Chia et al., 2001; Wang et al., 2001, 2004a), are omnipresent in most of the monitoring wells in the Choshuei alluvial fan, and the responses are different depending on the respective locations of the monitoring wells. These earlier investigations, however, did not report on the groundwater levels prior to the Chi-Chi earthquake. In order to demonstrate the puzzling results of these earlier investigations, the groundwater levels from the Yuanlin and Tzushan monitoring wells were plotted; the results are shown in Fig. 6(a) and (b). The two records are from the fourth aquifer in the Yuanlin area. The precipitation data for Central Taiwan are shown in Fig. 6(c), (d), and (f) and represent precipitation data for Taichung city, Chi-Chi, and His-Lou, respectively (See Fig. 1 for locations).

The groundwater levels of the two monitoring wells from
1995 to 2002 show fluctuations that can be attributed to the variations in seasonal water supply, variations in annual differences in water precipitation, and variations in the amount of water withdrawn. In general, the deformation detected by DInSAR in Central Taiwan conforms to the overall trend shown by the groundwater level in the Yuanlin area, with a relatively high groundwater table conforming with IM-4, a fair groundwater level conforming with IM-1 and IM-2, while during the time of IM-3 and IM-5, the groundwater level was relatively low.

\section{Discussion \\ 5.1 Sources of error in the DInSAR results}

There are several factors that can contribute to the phase signal in interferograms, such as phase contribution from topography, orbit, deformation, atmosphere, residual in the DEM, and various noises. During the process of differential interferometry, we used a $40-\mathrm{m}$ post size of the DEM of Taiwan, and precise orbit information for the ERS2 satellite was obtained from the Delft Institute for Earth-Oriented Space Research (Delft, The Netherlands). The use of highresolution DEM and precise orbit information eliminate the phase contributions of topography and orbit uncertainty. The profile chosen was relatively short in length; therefore, the atmospheric contribution should not have been significant. When the phase signal contributed from the residual of DEM is assessed, it is important to consider the altitude of ambiguity (Massonnet and Feigl, 1998), which represents the difference in height of topography, in order that only one interferometric fringe be generated. In an investigation of 


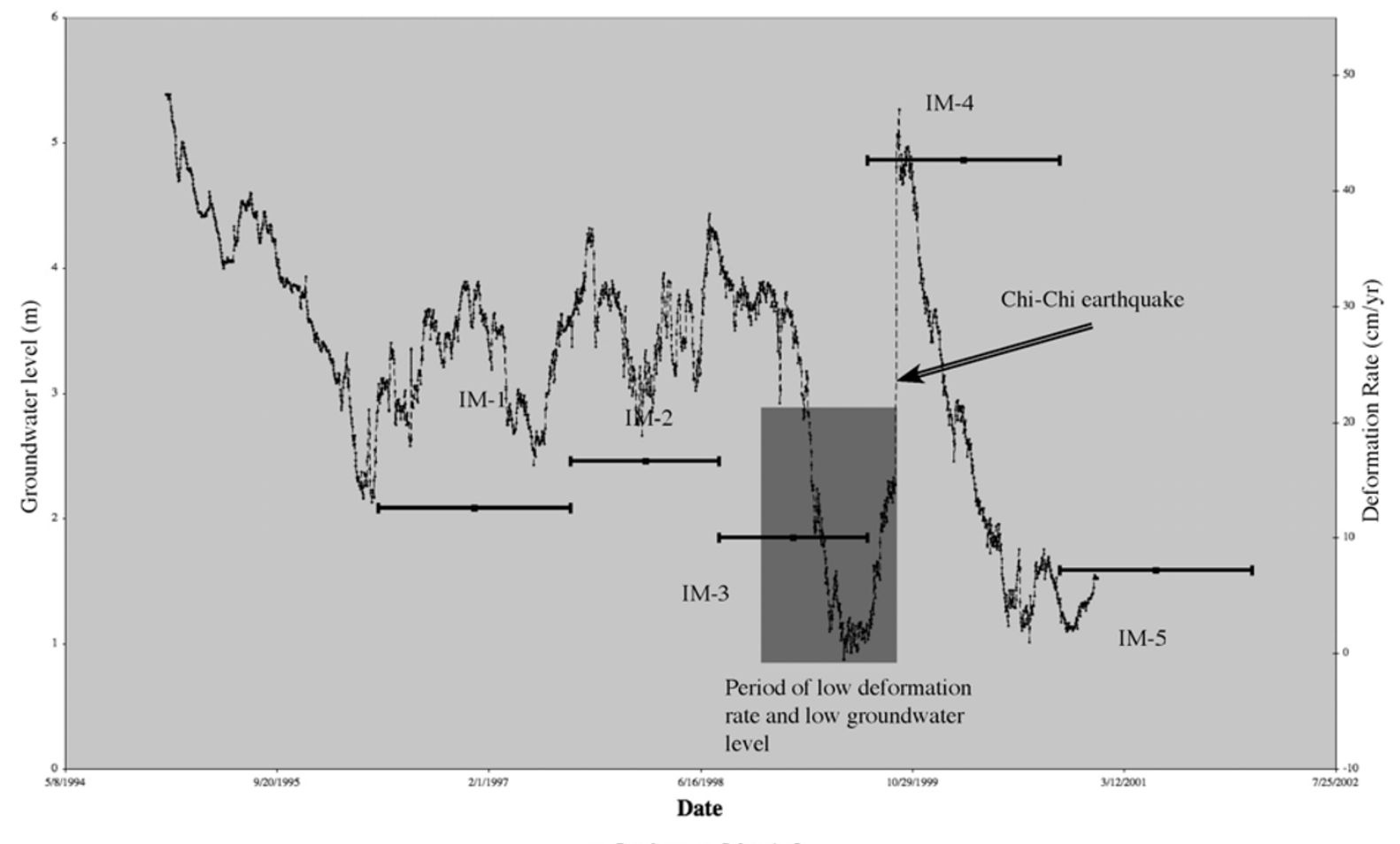

Fig. 5. Comparison of the deformation rate to groundwater level in Central Taiwan. The groundwater level data shown here is for the Yuanlin monitoring well.

crustal deformation, it is best to obtain an image pair with a large altitude of ambiguity so that the topographic information will not obscure the deformation information. Our five image pairs have an altitude of ambiguity as large as $300 \mathrm{~m}$ to as small as ( \pm ) $50 \mathrm{~m}$, and since the extracted profile is located in the Taichung Basin, which does not show any great variation in topography (Taichung Basin lies between 60 and $90 \mathrm{~m}$ a.s.1.) and the profile is relatively short (approximately $15 \mathrm{~km}$ ), the effect of the DEM residual is small in our data. In the worse case scenario, which would be when topographic information is not eliminated properly during the interferometric processing, the whole Taichung Basin will generate about half a fringe, and since our profile does not span the full Taichung Basin, most of the information extracted from our data is deformation signal.

\subsection{Water level and the fallen water level}

The groundwater level of both the Yuanlin and Tzushan monitoring wells exhibited many fluctuations. By visually inspecting the fluctuations, it was possible to separate the first-order signal (from Chi-Chi earthquakes) from other signals. The sharp rise in groundwater level in Yuanlin and its sharp fall in Tzushan mark the incidence of the Chi-Chi earthquake itself, with the change in groundwater level recorded exceeding $4 \mathrm{~m}$ at both sites. Other recorded fluctuations are less notable in comparison to the coseismic change. However, prior to the onset of the earthquakeinduced groundwater level changes, there was a period of time that the groundwater levels in both the Yuanlin and Tzushan monitoring wells were relatively low compared to other times reported in the records. This is particularly observable in the Yuanlin well, where the well exhibited the lowest groundwater level of the whole recorded period during that time, whereas during that same period the groundwater level in the Tzushan well was relatively low and exhibited frequent large fluctuations. The groundwater level started to drop approximately 200 days prior to the Chi-Chi earthquake and steadily decreased-with some fluctuations; about 50 days prior to the earthquake the trend reversed, and the groundwater level slowly increased. The Tzushan well is located on the tip of the Choshuei alluvial fan in Central Taiwan and is an unconfined aquifer; consequently, it is more likely to be affected by rainfall and the groundwater level is roughly in phase with the rainfall record. This would suggest that the increase in groundwater level is a reflection of the rainfall in the area. On the other hand, there is no straightforward explanation for the behavior of the groundwater level in the Yuanlin area. The Yuanlin well is in the Choshuei alluvial fan and is the fourth aquifer from the surface; therefore, rainfall should have only a minimal influence on the groundwater level of this well, suggesting that the large-scale drop in groundwater in the Yuanlin well may be caused by other means that extracted water from the aquifer. Wang et al. (2005) indicated that the groundwater of the Choshuei Alluvial fan in Central Taiwan has various isotope components that can be related to the other parts of the strata. Specifically, between January and March of 1999 to after the Chi-Chi earthquake the isotope composition of the groundwater in the lower aquifer has shifted toward that of the surface water. This indicates the possibility of conduits for groundwater and that substances have moved within the strata during this time. Therefore, a likely scenario is that prior to the onset of the earthquake, the 


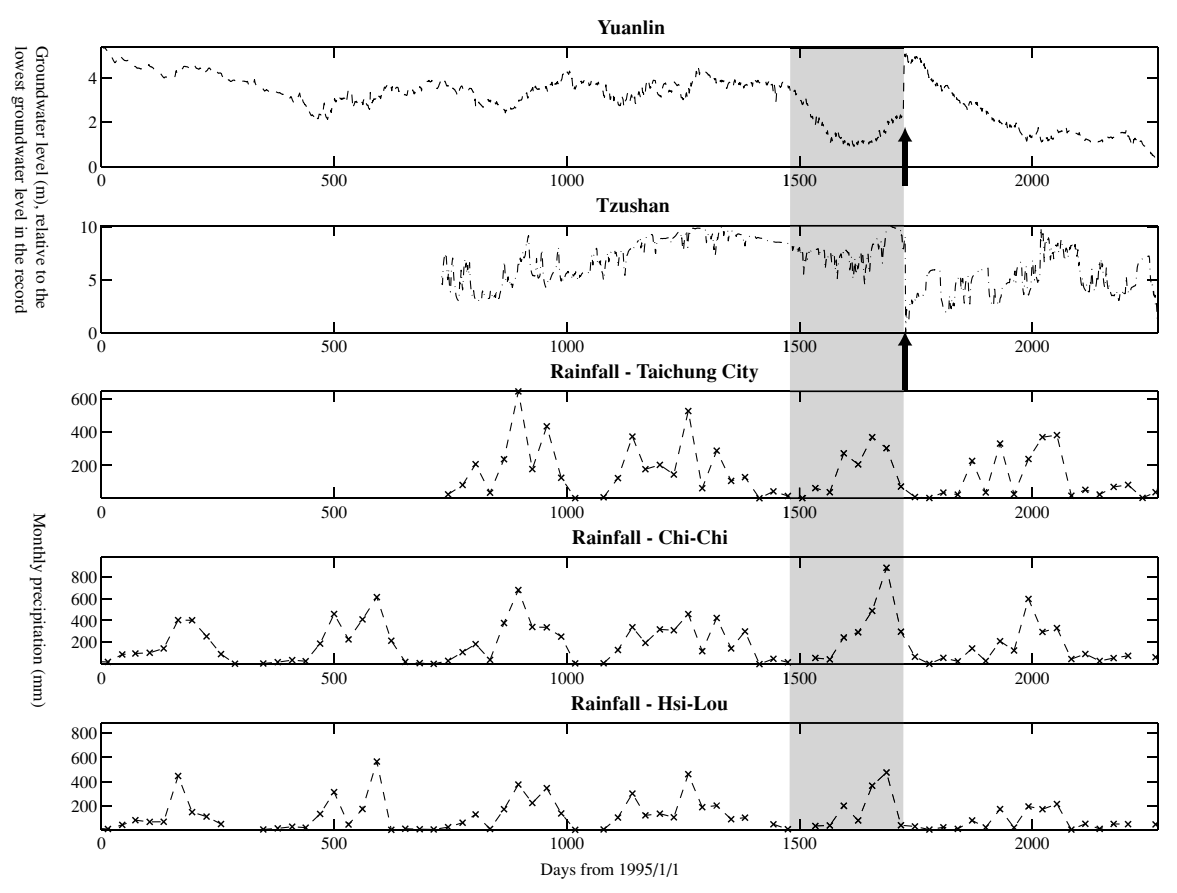

Fig. 6. The top two panels show groundwater levels of the Yuanlin and Tzushan monitoring wells, respectively. The lower three panels show the precipitation records of the same period in Central Taiwan (Taichung city, Chi-Chi, and His-Lou; see Fig. 1). Shaded gray areas indicate the time of relatively low groundwater levels before the Chi-Chi earthquake (indicated by black arrows in the Yuanlin and Tzushan groundwater records). The groundwater levels in either well does not necessarily fluctuate with the precipitation.

aquifer in the Central Taiwan region led to an extraction of groundwater in both aquifers in the footwall.

\subsection{Lowered deformation rate}

In Central Taiwan, the deformation rate observed by DInSAR is relatively low prior to the event of the Chi-Chi earthquake, which subsequently caused an increase in the respective deformation rate and a sharp increase in groundwater level, as illustrated by IM-3 of the deformation time series in Fig. 5. Lee et al. (2002) indicated that the volumetric strain change in Taiwan correlates with the change of groundwater level in Central Taiwan; however, many researchers regard the changes in groundwater level as being related to the release of water by the consolidation of the sediment caused by earthquake (Wang et al., 2003). In the former case, the change in groundwater level represents, firstly, a strainmeter in the ground and, as such, is related to the surface deformation observed from geodetic measurements. On the other hand, if the change in the groundwater level is mainly caused by the consolidation of the sediment, then the surface deformation observed by geodetic measurement would imply an increase or decrease in the volume of the groundwater. Previous research (Yu et al., 2001) and our own coseismic interferogram indicate that coseismic deformation in the footwall of Chelungpu fault of Central Taiwan is on the order of tens of centimeters and as large as $1.1 \mathrm{~m}$ in horizontal motion. This suggests that earthquakes and tectonics are the main factors producing the surface displacement in the coseismic period. As such, our suggestion is: prior to the earthquake-working on the assumption that the tectonic motion in Central Taiwan area stays constant- the decrease in groundwater level would be responsible for the surface subsidence. The combined effect of tectonic motion and the surface subsidence would explain the low deformation rate observed prior to the Chi-Chi earthquake in Central Taiwan.

Although reports of groundwater fluctuation prior to an earthquake are common, most of these only show fluctuations days before the earthquake. However, in this study, both the DInSAR measurements and groundwater observations demonstrate that approximately 100 days prior to the Chi-Chi earthquake there was a time of low deformation rate and decreasing groundwater level with twice the amplitude of normal fluctuation in Central Taiwan. This would naturally lead to an implication of "earthquake precursor". However, our work does not directly substantiate this. Rather, it points to several areas that require further research, such as: was the change in the groundwater level caused by a smaller earthquake or by the continuous tectonic stress exerted in this area? Did the leaked groundwater trigger the earthquake? Will this type of phenomenon occur in other earthquake or is it simply a one-time event? Many of these questions cannot be answered by geodetic observation or monitoring groundwater level alone. A more collaborative project is needed to explore any one of these questions.

Finally, previous studies have shown that the Chi-Chi earthquake had an impact on deformation styles in various locations in western Taiwan (Chang et al., 2004). Both the Hukou fault (north of the northern end of the Chelungpu fault) and the Houjiali fault (southwestern Taiwan) show changes in their deformation pattern during and after the occurrence of the Chi-Chi earthquake; more specifically, the deformation rate in Hukou area also shows a decrease before the Chi-Chi earthquake, although the immediate coseismic deformation is trivial in these two areas. Since the aquifers of Central Taiwan do not extend northward to the 
Hukou area or southward to the Tainan area, the geodetic responses in these two areas can not be explained by the changes in the groundwater level in Central Taiwan. It would imply that the tectonics might play a role in the surface deformation observed.

\section{Conclusions}

Deformation patterns during various time periods in Central Taiwan were constructed by the radar interferometry technique (DInSAR). The coverage times of the deformation patterns span from 1996 to 2002. During this time, the Chi-Chi earthquake contributed to large-scale deformation to Central Taiwan, the effects of which can be seen in the deformation time series.

DInSAR revealed a period of low deformation rate immediately before the occurrence of the Chi-Chi earthquake in the Central Taiwan, and a similar effect can be seen in the groundwater level recorded in the monitoring wells in both the Yuanlin and Tzushan areas. This low deformation rate and low groundwater levels lasted for more than 1000 days and ended with the occurrence of the earthquake. The lower deformation rate may have been-partially — caused by the leakage of groundwater to the lower aquifers or streams.

The effect of the Chi-Chi earthquake on the neotectonic deformation can be seen not only in Central Taiwan but also in the areas north to the Hukou area and south to the Tainan tableland where either in deformation rate or in deformation pattern can be observed.

Acknowledgments. The authors would like to thank Dr. Gerald Bawden of the USGS, Dr. Shui-Beik Yu, and the editor for many critical ideas; this paper has been significantly improved with their help. The work is funded by Ministry of Education, grant number A-91-N-FA07-7-4.

\section{References}

Akita, F. and N. Matsumoto, Hydrological responses induced by the Tokachi-Oki Earthquake in 2003 at hot spring wells in Hokkaido, Japan, Geophysical Research Letters, 31, L16603, doi:10.1029/ 2004GL020433, 2004.

Angelier, J., J. C. Lee, H. T. Chu, and J. C. Hu, Reconstruction of fault slip of the September 21st, 1999, Taiwan Earthquake in the asphalted surface of a car, park, and co-seismic slip partitioning, Journal of Structural Geology, 3, 345-350, 2003a.

Angelier, J., J. C. Lee, J. C. Hu, and H. T. Chu, Three-dimensional deformation along the rupture trace of the September 21st, 1999, Taiwan Earthquake: A case study in the Kuangfu School, Journal of Structural Geology, 3, 351-370, 2003b.

Bawden, G. W., W. Thatcher, R. S. Stein, K. W. Hudnut, and G. Peltzer, Tectonic contraction across Los Angeles after removal of groundwater pumping effects, Nature, 6849(412), 812-815, 2001.

Burgmann, R., P. A. Rosen, and E. J. Fielding, Synthetic aperture radar interferometry to measure Earth's surface topography and its deformation, Annual Review of Earth and Planetary Sciences, 28, 169-209, 2000.

Chang, C. H., Y. M. Wu, T. C. Shin, and C. Y. Wang, Relocation of the 1999 Chi-Chi Earthquake in Taiwan, Terrestrial Atmospheric and Oceanic Sciences, 3, 581-590, 2000.

Chang, C. P., K. S. Chen, C. T. Wang, and J. Y. Yen, Application of space-borne radar interferometry on crustal deformations in Taiwan: A perspective from the nature of events, Terrestrial Atmospheric and Oceanic Sciences, 3, 523-543, 2004.

Chia, Y. P., Y. S. Wang, J. J. Chiu, and C. W. Liu, Changes of groundwater level due to the 1999 Chi-Chi Earthquake in the Choshui River Alluvial Fan in Taiwan, Bulletin of the Seismological Society of America, 5, 1062-1068, 2001.

Dahlen, F. A., J. Suppe, and D. Davis, Mechanics of fold-and-thrust belts and accretionary wedges; Cohesive Coulomb Theory, Special section;
S. Thomas Crough memorial JGR. Journal of Geophysical Research. B, 89, 10,087-10,101, 1984.

Hsieh, M. L., Y. H. Lee, T. S. Shih, S. T. Lu, and W. Y. Wu, Could we have pre-located the northeastern portion of the 1999 Chi-Chi Earthquake rupture using geological and geomorphic data?, Terrestrial Atmospheric and Oceanic Sciences, 3, 461-484, 2001.

Hsu, K. C. and C. C. Tung, On estimating the earthquake-induced changes in hydrogeological properties of the Choshuishi Alluvial Fan, Taiwan, Hydrogeology Journal, 3, 467-480, 2005.

Huang, F. Q., C. L. Jian, Y. Tang, G. M. Xu, Z. H. Deng, and G. C. Chi, Response changes of some wells in the mainland subsurface fluid monitoring network of China, Due to the September 21, 1999, Ms7.6 Chi-Chi Earthquake, Tectonophysics, 1-4, 217-234, 2004.

Jang, J. J., C. S. Lee, and Y. H. Chen, A preliminary study of earthquake building damage and life loss due to the Chi-Chi Earthquake, Journal of the Chinese Institute of Engineers, 5, 567-575, 2002.

Kao, H., Y. H. Liu, W. T. Liang, and W. P. Chen, Source parameters of regional earthquakes in Taiwan: 1999-2000 Including the Chi-Chi Earthquake sequence, Terrestrial Atmospheric and Oceanic Sciences, 3, 279-298, 2002.

King, C. Y., S. Azuma, G. Igarashi, M. Ohno, H. Saito, and H. Wakita, Earthquake-related water-level changes at 16 closely clustered wells in Tono, Central Japan, Journal of Geophysical Research, 104, 1307313082, 1999.

Lee, J. C., Y. G. Chen, K. Sieh, K. Mueller, W. S. Chen, H. T. Chu, Y. C. Chan, C. Rubin, and R. Yeats, A vertical exposure of the 1999 surface rupture of the Chelungpu Fault At Wufeng, Western Taiwan: Structural and paleoseismic implications for an active trust fault, Bulletin of the Seismological Society of America, 5, 914-929, 2001.

Lee, M., T. K. Liu, K. F. Ma, and Y. M. Chang, Coseismic hydrological changes associated with dislocation of the September 21, 1999 Chichi Earthquake, Taiwan, Geophysical Research Letters, 29, 1824, doi:10. 1029/2002GL015116, 2002.

Lin, A., T. Ouchi, A. Chen, and T. Maruyama, Co-seismic displacements, folding and shortening structures along the Chelungpu Surface Rupture Zone occurred during the 1999 Chi-Chi (Taiwan) Earthquake, Tectonophysics, 3-4, 225-244, 2001.

Lin, C.-W., H.-C. Chang, S.-T. Lu, T.-S. Shih, and W.-J. Huang, An introduction to the active faults of Taiwan, 2nd Edition, Central Geological Survey, Ministry of Economic Affairs, 2000.

Lin, Y. B., Y. C. Tan, T. C. J. Yeh, C. W. Liu, and C. H. Chen, A viscoelastic model for groundwater level changes in the Cho-Shui River Alluvial Fan after the Chi-Chi Earthquake in Taiwan, Water Resources Research, 40 , W04213, doi:10.1029/2003WR002412, 2004.

Lundberg, N., D. L. Reed, C. S. Liu, and J. Lieske, Forearc-basin closure and arc accretion in the submarine suture zone south of Taiwan, Tectonophysics, 274, 5-23, 1997.

Ma, K. F., E. E. Brodsky, J. Mori, C. Ji, T. R. A. Song, and H. Kanamori, Evidence for fault lubrication during the 1999 Chi-Chi, Taiwan, Earthquake (Mw7.6), Geophysical Research Letters, 30, 1244, doi:10.1029/2002GL015380, 2003.

Massonnet, D. and K. L. Feigl, Radar interferometry and its application to changes in the Earth's surface, Reviews of Geophysics, 4, 441-500, 1998.

Matsumoto, N., G. Kitagawa, and E. A. Roeloffs, Hydrological response to earthquakes in the Haibara Well, Central Japan-I. Groundwater level changes revealed using state space decomposition of atmospheric pressure, rainfall and tidal responses, Geophysical Journal International, 3, 885-898, 2003.

Montgomery, D. R. and M. Manga, Streamflow and water well responses to earthquakes, Science, 300, 2047-2049, 2003.

Mouthereau, F., J. Angelier, and J. C. Lee, The 21-September-1999 Earthquake: Structural inheritance and basement involvement at the front of the Taiwan Mountain, Comptes Rendus De L Academie Des Sciences Serie Ii Fascicule a-Sciences De La Terre Et Des Planetes, 1, 93-103, 2001.

Quattrocchi, F., R. Pik, L. Pizzino, M. Guerra, P. Scarlato, M. Angelone, M. Barbieri, A. Conti, B. Marty, E. Sacchi, G. M. Zuppi, and S. Lombardi, Geochemical changes at the Bagni Di Triponzo thermal spring during the Umbria-Marche 1997-1998 seismic sequence, Journal of Seismology, 4, 567-587, 2000.

Roeloffs, E., M. Sneed, D. L. Galloway, M. L. Sorey, C. D. Farrar, J. F. Howle, and J. Hughes, Water-level changes induced by local and distant earthquakes at long valley caldera, California, Journal of Volcanology and Geothermal Research, 3-4, 269-303, 2003.

Seno, T., S. Stein, and A. E. Gripp, A model for the motion of the Philip- 
pine Sea Plate consistent with Nuvel-1 and geological data, Journal of Geophysical Research, B, Solid Earth and Planets, 98, 17,941-17,948, 1993.

Shin, T. C., Some seismological aspects of the 1999 Chi-Chi Earthquake in Taiwan, Terrestrial Atmospheric and Oceanic Sciences, 3, 555-566, 2000.

Song, S. R., W. Y. Ku, Y. L. Chen, Y. C. Lin, C. M. Liu, L. W. Kuo, T. F. Yang, and H. J. Lo, Groundwater chemical anomaly before and after the Chi-Chi Earthquake in Taiwan, Terrestrial Atmospheric and Oceanic Sciences, 3, 311-320, 2003.

Suppe, J., Kinematics of arc-continent collision, flipping of subduction, and back-arc spreading near Taiwan, Memoir of the Geological Society of China, 6, 21-33, 1984.

Tanaka, H., C. Y. Wang, W. M. Chen, A. Sakaguchi, K. Ujiie, H. Ito, and M. Ando, Initial science report of shallow drilling penetrating into the Chelungpu Fault Zone, Taiwan, Terrestrial Atmospheric and Oceanic Sciences, 3, 227-251, 2002.

Teng, L. S., Extensional collapse of the Northern Taiwan Mountain Belt, Geology, 10, 949-952, 1996.

Tsai, Y. B., T. M. Yu, H. L. Chao, and C. P. Lee, Spatial distribution and age dependence of human-fatality rates From the Chi-Chi, Taiwan, Earthquake of 21 September 1999, Bulletin of the Seismological Society of America, 5, 1298-1309, 2001.

Wang, C. H., C. Y. Wang, C. H. Kuo, and W. F. Chen, Some isotopic and hydrological changes associated with the 1999 Chi-Chi Earthquake, Taiwan, Island Arc, 1, 37-54, 2005.

Wang, C. Y., L. H. Cheng, C. V. Chin, and S. B. Yu, Coseismic hydrologic response of an Alluvial Fan to the 1999 Chi-Chi Earthquake, Taiwan,
Geology, 9, 831-834, 2001.

Wang, C. Y., D. S. Dreger, C. H. Wang, D. Mayeri, and J. G. Berryman, Field relations among coseismic ground motion, water level change and liquefaction for the 1999 Chi-Chi $(\mathrm{M}-\mathrm{W}=7.5)$ Earthquake, Taiwan, Geophysical Research Letters, 30, 1890, doi:10.1029/2003GL017601, 2003.

Wang, C. Y., C. H. Wang, and C. H. Kuo, Temporal change in groundwater level following the $1999(\mathrm{M}-\mathrm{W}=7.5)$ Chi-Chi Earthquake, Taiwan, Geofluids, 3, 210-220, 2004a.

Wang, C. Y., C. H. Wang, and M. Manga, Coseismic release of water from mountains: Evidence from the $1999(\mathrm{M}-\mathrm{W}=7.5)$ Chi-Chi, Taiwan, Earthquake, Geology, 9, 769-772, 2004b.

Yu, S. B., H. Y. Chen, and L. C. Kuo, Velocity field of GPS stations in the Taiwan Area, Tectonophysics, 1-3, 41-59, 1997.

Yu, S. B., L. C. Kuo, Y. J. Hsu, H. H. Su, C. C. Liu, C. S. Hou, J. F. Lee, T. C. Lai, C. C. Liu, C. L. Liu, T. F. Tseng, C. S. Tsai, and T. C. Shin, Preseismic deformation and coseismic displacements associated With the 1999 Chi-Chi, Taiwan, Earthquake, Bulletin of the Seismological Society of America, 5, 995-1012, 2001.

Yu, S. B., Y. J. Hsu, L. C. Kuo, H. Y. Chen, and C. C. Liu, GPS measurement of postseismic deformation following the 1999 Chi-Chi, Taiwan, Earthquake, Journal of Geophysical Research-Solid Earth, 108, 2520, doi:10.1029/2003JB002396, 2003.

J.-Y. Yen (e-mail: jyyen@csrsr.ncu.edu.tw), K.-S. Chen, C.-P. Chang, and S. M. Ng 